\title{
Colonizar con la mirada
}

\author{
Colonize with the look
}

M.Sc. Rosalía Gil Fernández*

\begin{abstract}
RESUMEN
El propósito de este artículo es visualizar y analizar sí la mirada hegemónica hacia la mujer, establecida durante la conquista latinoamericana aún se prolonga en la contemporaneidad, y sí esta mirada, perpetúa un discurso de poder estructurado e impuesto mediante técnicas específicas de sujeción y apropiación, que han contribuido en la construcción de una subjetividad marginada.La propuesta es que la mirada que produce desigualdades podría revertirse por medio de la divulgación de las voces de la otredad, como una posible resistencia al poder colonial, reflejado en la Colonialidad del Poder que prevalece en la modernidad.
\end{abstract}

Palabras clave: mirada, poder, mujer, cuerpo, colonia.

\begin{abstract}
The purpose of this article is to visualize and analyze if the hegemonic way of looking at women established during colonial times en Latin America, in colonial times, still prevails nowadays, and if this look perpetuates a discourse of power structured and imposed, through specific techniques of subjection and appropriation, that have contributed in the construction of a marginal subjectivity. The proposal is that this look that produces inequality could possibly be reversed though the divulgation of the voices of those others, as a possible resistance to the colonial power, reflected in the Coloniality of Power that prevails in modern times.
\end{abstract}

Key Words: Look, power, women, body, colony.

* Universidad de Costa Rica. Maestría Académica en Psicología. Costa Rica. Correo electrónico: rosaliagil1@ hotmail.com

Recepción: 4/9/2018 Aceptación: $5 / 12 / 2018$ 


\section{Introducción}

El propósito de este trabajo es visualizar y analizar la mirada hegemónica hacía la mujer latinoamericana, desde la conquista hasta la modernidad, mediante el hilado del trabajo de diferentes autores implicados en el tema. La premisa a desarrollar es que la mirada de los conquistadores hacia la mujer indígena, se dio desde un discurso basado en el poder, que desembocó en el racismo, la apropiación y la dominación. En este sentido, Foucault afirma lo siguiente sobre el ejercicio del poder:

¿De qué disponemos hoy para hacer un análisis no económico del poder? De bien poco, creo. Disponemos antes que nada de la afirmación de que el poder no se da, no se intercambia ni se retoma, sino que se ejerce en acto. Disponemos también de otra afirmación según la cual el poder no es principalmente mantenimiento y reproducción de las relaciones económicas, sino, ante todo, una relación de fuerzas. El poder es esencialmente el que reprime; el poder reprime por naturaleza, a los instintos, a una clase, a individuos. El poder siendo el despliegue de una relación de fuerzas, debería ser analizado en términos de lucha. (Foucault, 1992, p. 24)

Siguiendo esta línea de pensamiento, se puede plantear que el poder en la Conquista se ejerció a partir de una relación de fuerzas, una fuerza amparada en el discurso de un continente ilustrado que debía convertir al otro, y la otra fuerza, la de un continente recién entrado en los anales de la historia, que según la mirada de los conquistadores, estaba sumergido en la barbarie. Esta interacción de fuerzas desiguales llevó a los conquistados, a la sujeción, la apropiación y la dominación.

Sobre este tema, es importante recordar que para Kant, la Ilustración representa la salida de la minoría de edad de los pueblos civilizados, situando a los europeos en la Historia Universal, como dueños y señores en lo que se consideraba el Centro del Mundo. Con la conquista de América, se instaura la modernidad y se inventa un nuevo continente a semejanza de esa Europa ilustrada. Una tierra diferente que al ser promesa y futuro era también un lugar culturalmente amenazante que habría que ilustrar, cambiar y conquistar.

Asimismo, para Mignolo (2007) con Edmundo O’Gorman y su Invención de América, escrita en 1958, el mar deja de ser el límite del mundo y el Continente Europeo se convierte en amo y señor de lo conocido y por conocer de esa tierra recién descubierta, donde habitaban criaturas totalmente ajenas a la experiencia occidental. A 
partir de esa diferencia entre ambos, se establece en el Continente Americano, una geopolítica del conocimiento basada en la otredad, la cual se asienta en dos vertientes, la primera se basa en:

(...) el valor humano que se asigna a cada uno de los tres hijos de Noé: a Cam, el más despreciable, se le atribuye en los mapas antiguos, a África; a Sem quien ofreció esperanzas y dio signos de buen comportamiento, se le identifica con Asia y a Jafet, el aliento, la expansión y la visión de futuro, se le asienta en Europa. (Mignolo, 2003, p.45)

Este discurso gira en torno a un eurocentrismo dicotómico, centrado en el racismo y la verticalidad, donde Europa se convierten en el centro que dicta la norma, Asia en lo exótico que salvaguarda la historia sagrada, África en la esclavitud servil y América, en la extraña cuna de la barbarie. Para Mignolo, los procesos hegemónicos ejercidos en la colonia, convirtieron a la colonialidad en la cara oculta de la modernidad. En este sentido, él afirma que desde entonces se establecen patrones de pensamiento y comportamiento hegemónico que continúan vigentes por medio de la globalización, perpetuando los antiguos binomios basados en opuestos, como punto de referencia ideológica, para justificar la intervención cultural, social y económica de las personas y los pueblos, estableciendo y definiendo así la Colonialidad del poder en el mundo latinoamericano actual. América se inventa y se establece desde el Occidentalismo: “concepto geopolítico y base del saber desde el que se determinaron todas las categorías de pensamiento y todas las clasificaciones del resto del mundo". (p. 60)

La segunda vertiente de la geopolítica del conocimiento se basa en que lo femenino se encuentra subyugado a lo masculino:

La cuestión de género y la sexualidad se estructuró en la civilización occidental, en el relato bíblico, en la historia de Adán y Eva y también en la historia del diluvio y en el hecho de que los tres descendientes de Noé fueron varones (Jafet, Sem y Cam). Por el primero, la estructura ética de la relación hombre/mujer se asienta en la relación de la pareja masculino/femenino. (Mignolo, 2003, p.45)

Este tipo de dominación se basa en una mirada superior establecida en la época de la conquista y documentada en los Diarios de Navegación de Colón, (1942) inéditos hasta que Bartolomé de las Casas los adecuó en su Historia de las Indias, se ha perpetuado y ha influenciadodesde entonces en la construcción de la subjetividad de la 
mujer latinoamericana, por medio de ese poder hegemónico al que hace referencia Mignolo.

A continuación, se analizara la mirada del cuerpo femenino subyugado a lo masculino, desde la conquista hasta la contemporaneidad.

\section{En la Conquista}

Para Durán Luzio, en los Textos de Navegación que contienen la documentación de lo que Colón percibió cuando llegó por primera vez en el nuevo continente, se constata la forma en que se establece una mirada degradante hacia las personas indígenas, esos seres diferentes categorizados como Los Otros. En ese entonces, la mujer que los conquistadores observaron fue laque Durán Luzio (1999) menciona en Entre la Espada y el Falo, como recién encontrada y pronto sometida; mujer presa de una mirada voyeurista y depredadora que desde entonces, clasifica a la existencia humana en concepciones ideológicas binarias como, superior/inferior, Norte/Sur, masculino/femenino, colonizador/colonizado. Con base a estas concepciones, el autor se pregunta si se establece desde entonces, el falo como espada y si la marginalización de la mujer hispanoamericana, encuentra su explicación en esos primeros registros coloniales sobre la formación de una sociabilizad mestiza en nuestro continente:

12 de Octubre, 1942:"Ellos andan todos desnudos como su madre los parió, y también las mujeres, aunque no vide más de una harto moza." (Durán Luzio, 1999, p.19)

17 de Octubre: "Aquí hallaron que las mujeres casadas traían bragas de algodón, las mozas no, sino salvo algunas que eran ya de edad de diez y ocho años." (1999, p.20)

21 de Octubre: "Y en los otros lugares todos los hombres hacían esconder sus mujeres de los cristianos por celos, más allí no, (en La Hispagnola) hay muy lindos cuerpos de mujeres y ellas las primeras que venían a dar gracias al cielo y traer cuanto tenían, en especial cosas de comer, no menos dis que hacían las mujeres en otras partes que se escondiesen.” (1999, p.22)

12 de Diciembre de 1942: "Y finalmente tomaron una mujer, que no pudieron más, porque yo (Colón) les había mandado que tomasen algunos para honrallos y hacelles perder el miedo y si hobiesen alguna cosa de provecho, como no parece poder ser otra cosa según la fermosura de la tierra; y si trujeron una mujer muy moza y hermosa a la nao, y habló con aquellos indios, porque todos tenían una lengua. Hízola el Almirante vestir y diole cuentas de vidrio y cascabeles y 
sortijas de latón y tornóla a virar a tierra muy honradamente, según su costumbre." (1999, p.20)

A través de estos relatos, se puede apreciar como el mismo Cristóbal Colón es él que percibe desde una mirada voyeurista la vida cotidiana de las mujeres indígenas. Este tipo de percepción masculina es a la que se refiere Cixous (1992) en la Risa de la Medusa, como una mirada apropiadora:"¡Cómo la mira! Cuando ella tiene los ojos cerrados; cuando él la comprende por completo, y ella es sólo esta forma hecha para él; cuerpo prisionero de su mirada." (1992, p.18.) Es ese tipo de mirada que degrada, aprisiona e inspecciona al otro-femenino como objeto de apropiación, recordándonos que "el sujeto, dentro del análisis existencial de la misoginia, siempre es masculino, fusionado con lo universal, y se diferencia del Otro, femenino, fuera de las normas universalizantes, en calidad de persona." (Butler, 1990, p. 44). Normas donde la mujer queda reducida a calidad de objeto.

En relación directa a esta forma de apropiación voyeurista, en Diciembre de 1942, durante el Segundo Viaje de Colón, luego de que la Santa María chocara contra un arrecife, quedaban 39 hombres en la Española, sucedió lo siguiente:

Preguntándoles el Almirante por los cristianos, que era lo que le dolía, respondieron que algunos eran muertos de enfermedad y otros se habían ido tierra adentro con sus mujeres, y aún muchas mujeres... no exacerbaran los vecinos tomándoles sus mujeres e hijas, que es con lo que más se injurian y agravian, como dondequiera, nunca ellos perecieran.... Les tomaban sus casas, muxeres e hijas para torpes usos. (1999, p.27, p.28)

Y además, un tiempo después, a raíz de ese acto vandálico plagado de violencia y destrucción, en Valladolid, el 28 de Julio de 1513 se culpa a las mujeres, decretando:

La corona de Castilla manda a indios e indias a cubrir su provocativa desnudez, espejo para la lujuria, puerta de ingreso al pecado y enfrenta al cristianismo.... Para que pudiesen aprender a regirse por sí mismos y dejar de vivir como los animales irracionales que parecían en el caos pecaminoso y demoníaco anterior a la llegada de la cruz. $(1999$, p.29, p.30)

Estas citas evidencian como la violencia se justifica, colocando la responsabilidad del agravio sucedido, en la provocativa desnudez de la mujer, que de ahora en adelante debe ser cubierta, para dejar de ser tentadora. Sobre esto, Durán 
Luzio, (1999) insinúa que Verpucio en Mundus Novus, (en su carta a Pedro de Médicis,) se atreve a ir un paso más allá, en su percepción y descripción de esos cuerpos desnudos y pecadores que provocan a los hombres. Son los cuerpos que mirados como objetos sexuales se convertirían en tentación peligrosa:

Las mujeres como te he dicho, aunque andan desnudas y son libidinosas, no tienen nada defectuoso en sus cuerpos, hermosos, oscuros y limpios, ni tampoco son tan groseras como alguno quizá podría suponer, porque aunque son carnosas, falta al a par de ello la fealdad... una cosa las que habían parido, por la forma del vientre y la estrechura, no se diferenciaban en nada de las vírgenes, y en otras partes del cuerpo parecían lo mismo, las cuales por honestidad no menciono...(Durán Luzio, 1999,p. 34)

(...) cuanto a la hermosura, decían los cristianos que no había comparación, así en los hombres como en las mujeres, y que son blancos más que los otros, y que entre los otros vieron dos mujeres mozas tan blancas como podían ser en España... creo que si anduvieran vestidos serían tan blancos como nosotros. $(1999$, p.42)

Lo cierto, es que estas manifestaciones culturales de la mujer indígena, estaban en total contraposición al imaginario masculino de la mujer europea. Ellos, ante la amenaza de lo novedoso y lo diverso, marginaron y explotaron a las mujeres indígenas, mirándolas exclusivamente como objetos sexuales provocadores.Sobre esto, el autor se pregunta: “¿Hasta tales grados expresó el extranjero el desajuste y temor a lo diverso? ¿O lo escrito al respecto no son más que otras frases tendenciosas para comenzar a marginar a la mujer del Nuevo Mundo?” (Durán Luzio, 1999, p.35).

Con base a lo anterior se puede constatar que ambos conceptos sobre el ideal femenino estaban entrelazados y que estas percepciones documentadas por los conquistadores, vendrían a será cara oculta de las técnicas de dominación en el ejercicio del poder, donde tal y como advierte Foucault, se clasifica, se sujeta y se rige el comportamiento humano, por medio de una biopolítica dirigida al cuerpo y a su posible utilidad.

En este sentido, es importante observar que en los escritos de Vespucio, este tipo de biopolítica se justifica con la clasificación de la mujer indígena como prostituta o mujer vendida: 
La puta es mujer pública y tiene lo siguiente: que anda vendiendo su cuerpo, comienza desde moza y no lo deja siendo vieja... y a cualquier hombre se da y le vende su cuerpo, por ser muy lujuriosa, sucia y sin vergüenza, habladora y muy viciosa en el acto carnal... y a las veces se pone colores o afeites en el rostro, por ser perdida y mundana. (Durán Luzio, 1999, p. 51)

Sobre los cuerpos desnudos dominados y destruidos, Mora en La Conquista del Sexo, escribe:

La evocación de los cuerpos desnudos que aparece de manera repetitiva en diferentes textos (de la época de la conquista) señala la profunda impresión que dicha condición deja en los recién llegados visitantes. La exaltación de la belleza, que podría haberse comprendido como mirada desinteresada, deja paso a una mirada depredadora. (Mora, 2009, p. 431)

Bajo esta mirada depredadora, el cuerpo de la mujer desnuda es ahora el que incita y perpetúalas miradas voyeuristas masculinas. Un cuerpo que debe dominarse y reprimirse, para que deje de ser una tentación carnal ante los ojos de los conquistadores. Tentación que eventualmente justificó no sólo la apropiación, sino la destrucción y la mutilación de esos cuerpos. Citando a Bartolomé de Las Casas, Mora afirma: “Otros ataban o liaban todo el cuerpo de paja seca, pegándoles fuego así los quemaban. Otros, y todos los que querían tomar la vida, cortábanles las manos.” (Mora, 2009 p. 435) Estas fueron las mujeres víctimasde esa mirada masculina europea, que justificó la violencia hacia la mujer indígena con base la supuesta amenaza que su diferencia y su otredad representaban.

En este sentido, Durán Luzio escribe: "el llamado descubrimiento de América si bien dio lugar a textos gloriosos, también aportó una página casi inédita a la historia de la inequidad humana.” (Durán Luzio, 1999, p.15) Esta fue la explotación, la destrucción y sujeción establecida con base a las diferencias culturales y étnicas, que se dio en nuestraAmérica, esa tierra inventada a la medida de Europa, que al ir siendo y dejando de ser, fue abriendo sus puertas y las de sus habitantes, especialmente las de sus mujeres, a un tipo de sujeción y represión que marcó los inicios de una subjetividad subyugada y oprimida que aún perdura en nuestros días.

\section{En la actualidad}

A raíz de lo anterior cabe preguntarse si efectivamente, ¿continúa perpetuándose una mirada inmersa en los parámetros de la Colonialidad del Poder, la discriminación y 
la represión, en la vivencia de la mujer latinoamericana actual?, ¿Qué significa ser mujer en este continente?

Para responder, es importante destacar que para los autores postcoloniales como Mignolo, la desigualdad y la verticalidad se instauran a partir de significados construidos dentro de saberes y poderes en competencia, estructurados durante siglos en los discursos pre-coloniales europeos, en los discursos coloniales y sucesivamente en los discursos de la Colonialidad del Poder prevalecen en la modernidad globalizada. En este sentido, la construcción del ser mujer ha ido paralela a la construcción del cuerpoobjeto y el ser-objeto, en una tierra cuya identidad fue usurpada desde la colonia y cuya percepción ha dado pie a una clasificación étnica, amparada en un discurso añejo, basado en la otredad, que justifica el abuso y la desigualdad.

En los Diarios de Colónse percibe cómo se manifiesta la apropiación de la mujer, dentro del binario masculino/femenino, apropiación que aún sigue vigente. Butler (1990) afirma que hoy en día, el cuerpo de la mujer ha llegado a considerarse "un mero instrumento o medio, con el que una serie de significados se relacionan sólo externamente," (Butler, 1990, p. 41) eliminando su calidad de sujeto. Esta objetivación de la mujer se refleja en los altos índices de violencia doméstica, en el aumento de femicidios, la explotación sexual comercial, y el abuso sexual intra y extra familiar, que se da hoy en día. La mujer-objeto también se visualiza en el tráfico de personas, ya sea con propósitos sexuales o laborales. Esta problemática de la mujer como forma de mercancía, ocupa el tercer lugar, luego del narcotráfico y del tráfico de armas, indicándonos que las mujeres en estos tiempos, continúan siendo miradas y utilizadas como posesiones aptas para el trueque. Esto se da especialmente en los países más empobrecidos, localizados en el extremo sur de nuestra tierra, los países del Sur-Sur, donde continúan siendo objeto de deseo e intercambio. Sobre este tema, Irigaray (1982) afirma que:

Las mujeres son intercambiadas no en tanto que mujeres, sino en tanto que se les compara con algo que les sería común-su cota en oro, o falo- con respecto con lo cual ellas representarían un más o un menos. Pero no un más o un menos de cualidades femeninas, evidentemente. Como ellas quedan abandonadas a las necesidades del consumidor, la mujer vale más en el mercado en función de una sola cualidad: la de ser un producto del trabajo del hombre. (Irigaray, $1982 \mathrm{p}$. 165) 
Esta objetivación de la mujer actual guarda un paralelismo con lo documentado por Durán Lucio, en la colonia, sobre el abuso a las mujeres indígenas percibidas como objetos sexuales intercambiables. Actualmente, este valor de intercambio, al igual que sucedía en ese tiempo, produce una desvalorización de la mujer y sus capacidades productivas con respecto al hombre, lo que también lleva a una clara feminización de la pobreza. Así mismo, actualmente, en los estratos sociales altos, la moda y las expectativas de belleza, son conducentes a los trastornos alimenticios, a la insatisfacción personal y a la transformación extrema de los cuerpos, que también las convierte en mercancías y objetos, presas de las miradas voyeuristas depredadoras, como sucedía en los tiempos coloniales.

Hoy en día, aunque estén situadas en la escala social ascendente, las mujeres profesionales no se escapan de la mirada apropiadora y desigual pues aún mantienen sus roles de pareja, madre, cuidadora y proveedora que reflejan un sistema patriarcal vertical desigual. En América Latina, las mujeres más pobres, especialmente las indígenas migran dentro y fuera de sus sitios de origen, dejando atrás a sus familias y costumbres, para exponerse a todo tipo de abusos y subordinarse en los trabajos domésticos explotadores, las maquilas, las ventas callejeras y los mercados. Así, para Irigaray (1982) lo que hoy hace posible el estatuto de las mujeres en el orden social, lo que asegura su fundamento y su razón de ser, es solamente el valor-objeto que produce su intercambio. Su valor se coloca bajo el precio que les pone la mirada masculina.

Es la circulación de las mujeres entre los hombres lo que establece el funcionamiento social, por lo menos el patriarcal. Lo que supone la apropiación de la naturaleza por parte del hombre, su transformación en función de criterios humanos definidos solamente por los hombres: su sumisión al trabajo, a la técnica; la reducción de sus cualidades materiales, corporales, sensibles, un valor abstracto de intercambio... La mujer virgen por el contrario, es puro valor de cambio. Ella no es más que la posibilidad, el lugar, el signo, de las relaciones entre los hombres. Madre, virgen, prostituta, tales son los roles sociales impuestos a las mujeres. (Irigaray, 1982, p. 173-174)

En este sentido, la descripción de la visión de la mujer latinoamericana actual que hacen otros autores del presente, no difiere mucho de la hecha por Durán Luzio, en tiempos de la conquista. En muchos países latinoamericanos existe una vasta disponibilidad de trabajadoras, generalmente indígenas, de muy bajo salario con horarios totalmente desproporcionados y sin seguridad social, donde además deben estar 
sexualmente disponibles. Muchas de ellas, trabajan de sol a sol para cubrir su alimentación. Esto sucede dentro de una desvalorización de la mujer y sus capacidades con respecto al hombre, con una clara feminización de las migraciones forzadas y del trabajo mal remunerado. La idea de América y sus habitantes indígenas, especialmente sus mujeres, como inferiores, proviene del tipo de poder vertical ligado a un fin último: la generación de dinero, divisas o capital, donde para conseguir esos fines, las personas se convierten en objetos. En los países económica y culturalmente desiguales, con altos porcentajes de pobreza, esto es especialmente cierto.

En este sentido, también Sassen (1998) afirma que "la creciente presencia de mujeres inmigrantes y de personas étnicamente diferentes, en las grandes ciudades, junto con una declinante clase media han facilitado la operación de los procesos de desvalorización." (Sassen, 1998, p. 119) La mayoría de ellas trabajan en oficios domésticos o en el sector informal, donde a menudo son humilladas y explotadas. Siguiendo esta línea de pensamiento, Gregorio Gil (1998) observa que en las mujeres que migran internacionalmente existe una mayor capacidad económica, que les permite un mayor poder en la toma de decisiones, pero la autoridad y la forma en que el dinero se gasta, continúa recayendo en los varones de la familia, perpetuando la desigualdad la verticalidad dentro de binomios opuestos. Ellas siguen siendo subordinadas al poder masculino y su papel como proveedoras no es valorado. Se observa un sentimiento de desadaptación en el país donde trabajan y en su país de origen cuando regresan, donde inclusive algunas parejas amenazan con quitarles los hijos si ellas no continúan enviándoles sus remesas, convirtiendo así la relación de madre-esposa-proveedora, en una relación perversa dentro de un ciclo de desigualdad.

Sin embargo, es importante destacar que también se ha observado que aunque la migración no representa una reivindicación en cuanto a la igualdad de condiciones, si les brinda una mayor libertad en la toma de decisiones, porque algunas mujeres en estas condiciones de vida, se atreven a dejar a sus parejas para buscar su independencia personal. La ruta migratoria vista así, tiene la posibilidad de convertirse en un escape que puede mejorar sus condiciones de vida:

Detrás de la justificación económica por la que estas mujeres inician su emigración, y que queda demostrada por su fidelidad a sus grupos domésticos en forma de remesas, su emigración termina constituyéndose en una vía de escape para ellas mismas. (Gregorio Gil, 1998, p. 243) 
Pero también se ha observado que a pesar de los cambios en autonomía y mayores ingresos de las mujeres más independientes, hay una lucha de poder donde son menoscabadas en su calidad de sujeto. Por ejemplo, España se ha convertido en el sueño de muchas latinoamericanas, pero la llegada a tierras españolas, sigue siendo sólo un sueño: el trabajo es duro y ellas continúan siendo vistas de arriba hacia abajo. Viven en la marginalidad, sirviendo a los que se encuentran en la escala social económicamente ascendente. Cuidan de sus niños, de sus adultos mayores y sus mascotas, estableciendo vínculos afectivos que son desgarradores cuando vienen las separaciones, produciéndose una explotación emocional. El fenómeno se constituye en un retorno al país colonizador, donde la sombra de las carabelas está siempre al asecho. Esta es la Colonialidad del Poder que en la actualidad se sigue ejerciendo dentro de una relación de desigualdad e indefensión.

En las migraciones intra-nacionales del área rural a las ciudades, se produce un fenómeno parecido: se adquiere una mayor autonomía pero la supremacía continúa siendo masculina porque ellos mantienen sus roles originales con respecto a los de las mujeres. Los estudios de Rivera Cusicanqui (1996) realizados en Bolivia en el año 1990, denotan un aumento en las ocupaciones femeninas por cuenta propia con un mayor servilismo adscrito a sus hogares. El abandono del lugar de origen se da a raíz de la pobreza donde las más jóvenes migran con fines educativos, con una transición en el servicio doméstico. Entre las de segunda generación, se da un proceso con redes de apoyo predominantemente urbanas, con tasas diferenciadas de crédito, produciendo una mayor explotación colectiva desde el mercado formal hacia el mercado informal.En estas generaciones, donde ellas se emparejan con personas ajenas a sus pueblos, hay una menor homogeneidad, pero se da un aumento en el alcoholismo, el desempleo masculino y la violencia doméstica que perpetúa el ciclo de la desigualdad. Este tema se ve reflejado en las afirmaciones de Teófila, indígena aymara, vendedora de pescado, que con apoyo familiar logra establecerse en La Paz a los 14 años de edad:

"He trabajado tres años de empleada, tres años he trabajado, después ya me he hecho de marido, después he dejado de trabajar un tiempito, después ya me he hecho de negocio de pescado... 
... ya fresco vendía, lana de colores también traía.. También se lavar ropa. Ah en toda forma he sabido ganar yo mi vida, um... he trabajado no más siempre, así he criado mis ch'itis." (Rivera Cusicanqui, 1996, p. 242)

Aunque las mujeres sean las principales proveedoras, la idea de "ayuda conyugal" siempre está vigente posicionándolas en una situación de desventaja con respecto a sus parejas. Esta situación, de la que Teófila nos habla es indicativa de la inequidad y la complementariedad presente en la Colonialidad del poder: "Me pegaba ps' harto, ahora mas bien no me pega, desde que me he casado, ya no me ha tocado..." (Rivera Cusicanqui, 1996, p. 260.) La de Teófila es la voz de la desigualdad y la otredad donde los esfuerzos realizados por la mujer son invisibilizados, como invisibilizada fue su condición de ser humano durante la conquista y la colonia.

La inequidad prevalece en los pueblos indígenas latinoamericanos, produciendo un tipo de desigualdad y de pobreza donde la cara externa de la inequidad continúa teniendo rostro de mujer.

\section{Cambiar desde la resistencia}

La pregunta que surge ante la evidencia de estos procesos de atrapamiento e indefensión, es cómo revertirlos para reivindicar a la mujer latinoamericana indígena para que vaya posicionándose en un sitio fuera de los procesos hegemónicos y aplastantes que los autores revisados destacan como la base y causa de la inequidad. La labor que conlleva al cambio se iniciaría desde la resistencia a esos procesos binarios culturalmente implantados, que se encuentran enquistados desde siempre en la vida desigual.

Este tipo de resistencia la encontramos documentada en autores como Kristeva, Cixous, de Sousa Santos, Quijano, Foucault y Mignolo. El cambio estaría en la resistencia presente en la escucha, la documentación y la divulgación de las voces de la otredad, las voces de las mujeres indígenas que tienen tantas historias personales y colectivas que relatar. Estaría en la divulgación de las manifestaciones de las Teófilas de nuestro continente. Estaría en lo que Mignolo (2007) describe como mirar desde los bordes del mundo por conocer. En lo que Foucault (1992) llama la contra-historia que habla desde el silencio de la sombra: 
La contra-historia que nace con el relato de la lucha de razas, hablará justamente de parte de la sombra, a partir de esa sombra. Sería el discurso de los que no poseen la gloria o, habiéndola perdido, se encuentran ahora en la oscuridad y en el silencio. (Foucault, 1992, p.63)

En este mismo sentido, para de Sousa Santos (2006) la resistencia a estos procesos hegemónicos consiste en reinventarse desde abajo, desde la sombra, desde lo que está oculto. Sería resignificar los discursos coloniales que permiten florecer el pensamiento de los acallados: los discursos que afirman y reconocen el espacio donde el pensamiento fue negado y se expresan desde los silencios por descubrir.

Mignolo habla de un Paradigma-otro que surge del silencio detrás de cada página del autor castellano sobre la colonia. Desde las voces de los marginados, las voces de los Otros, donde para él, el pensamiento fronterizo vendría a ser "el del rumor de los desheredados de la modernidad; aquellos para quienes sus experiencias y sus memorias corresponden a la otra mitad de la modernidad, esto es, a la colonialidad."(Mingolo, 2003, p.27). Esta transformación epistémica inmersa en la vida actual, vendría a representar un cambio desde las bases que fueron instaurando la Colonialidad del poder en nuestro Continente:

Un Paradigma-otro marca la discontinuidad en la historia de la modernidad, contada desde la perspectiva de la propia modernidad, e introduce la mirada opuesta. No, digamos, la mirada de Colón mirando a los indios mientras se acercaba a las costas, sino la de los indios mirando a ese objeto extraño, en el agua, que se acercaba a ellos. Esas dos miradas se ligaron, se entrelazaron en una relación de poder; se plantó la semilla de la Colonialidad del poder y con ella el paradigma silenciado durante mucho tiempo de quienes ven el mundo desde las costas a las que llegan los barcos, los ferrocarriles, los bancos, los aviones. (Mignolo, 2003, p. 32)

Dentro de esta misma línea ideológica que ha logrado implantar la Colonialidad del poder, Chakravorty Spivak expresa que (2006, p. 21) "el más claro ejemplo de violencia epistémica es el remotamente orquestado, extendido y heterogéneo proyecto de construir el sujeto colonial como el Otro.” El otro, el ajeno, el extraño, el diferente. Para ella, los movimientos de resistencia se establecen desde ese otro lado de los conceptos que dieron origen a la colonialidad. Se establecen desde el conocimiento asociado con una relación genealógica estratégica que nos permite re-construir la resignificación de los significados, dentro de la resistencia a una modernidad que para subsistir ha necesitado de la colonialidad y la otredad. La resistencia a esa violencia se 
establece dentro de una interrogación constante que logre re-significar los binarios que emergen desde la mirada objetivizante de los relatos originarios y absolutos que aún siguen vigentes.

$\mathrm{Y}$ en términos concretos a esa resistencia a la mirada inferiorizante que coloca a las personas dentro de binarios y opuestos, para Benhabib (2006, p. 192) "ni lo concreto ni la otredad del otro concreto pueden conocerse en ausencia de la voz del otro." Esas voces vendrían a lograr revertir, desde una instancia subalterna, la mirada maligna y voyeurista que niega y descalifica al Otro en su calidad de persona:

El movimiento antidialéctico de la instancia subalterna subvierte toda la ordenación binaria o de negación superadora (sublatory) del poder y el signo; difiere el objeto de la mirada ("porque aún ahora me miras/pero nunca me ves") y le confiere un movimiento estratégico, que aquí podemos, por analogía, llamar el movimiento de pulsión de muerte. El ojo maligno, que no es nada en sí mismo, existe en sus huellas letales o en efectos como una forma de iteración que detiene el tiempo (muerte/caos) e inicia un espacio de intercalación que articula política/psiquis, sexualidad/raza. Lo hace en una relación que es diferencial y estratégica antes que originaria, ambivalente antes que acumulativa, duplicante antes que dialéctica.

El juego del ojo maligno es camuflado, invisible en la actividad corriente de mirar y hacer presente, mientras está implicado en la mirada petrificante y sin parpadeos que cae, como la Medusa, sobre sus víctimas, repartiendo la muerte, extinguiendo tanto la presencia como el presente. Hay una re-presentación específicamente femenina de la subversión política en esta estrategia del ojo maligno. La re-negación de la posición de la mujer migrante, su invisibilidad social y política, es usada por ella como secreto de la venganza, mímesis." (Bhabha, 1994, p.77-78)

La labor desde la resistencia, por lo tanto, consiste en resignificar los relatos, desde una mirada nueva que revierta al ojo maligno. "Es tiempo de aprender a liberarnos del espejo eurocéntrico donde nuestra imagen es siempre, necesariamente, distorsionada. Es tiempo, en fin, de dejar de ser lo que no somos." (Quijano, 2000, p. 242)

La resistencia desde la diferencia es pensar desde la deconstrucción de los relatos que contienen las divisiones de raza que utilizaron los españoles para ordenar, administrar y gobernar los territorios latinoamericanos y sus habitantes. Se trata de develar la lógica encubierta, de re-significar la historia de los pueblos que han formado parte de una continuidad histórica percibida a través de una mirada parcializada. Es a lo 
que se refiere Bhabha cuando habla de revertir el discurso colonial como aparato de poder. La resistencia consiste en resignificar los relatos de las mujeres desde otra mirada donde eventualmente, "para superar el androcentrismo y el sexismo, es preciso cambiar las valoraciones culturales así como sus expresiones legales y las prácticas que privilegian la masculinidad y niegan igual respeto a las mujeres.” (Fraser, 1997, p.33)

Este tipo de resignificación lograría revertir esa mirada petrificante e inferiorizante que hemos construido particularmente alrededor del cuerpo de la mujer y su circunstancia. Las voces de las mujeres silenciadas, marcarían la resistencia a esa mirada ancestral, enrumbándolas hacia un mundo de mayor equidad, respeto, tolerancia e inclusión.

\section{Conclusión}

Por medio de los autores mencionados, se ha logrado evidenciar la forma cómo la mirada impuesta desde el tiempo de la conquista, ha llevado a la apropiación, la descalificación y la dominación de la mujer indígena latinoamericana, que con su forma de ser amenazaba lo establecido, convirtiéndola en el Otro, el diferente, el objeto de apropiación. El anterior recorrido expone cómo desde la conquista de América, se han venido instaurando formas de mirar a las personas consideradas diferentes, que dieron paso a la desigualdad y la verticalidad desde los binomios superior/inferior, arriba/abajo, establecidos por parámetros occidentales europeos, que catalogaron a las personas que habitaban las nuevas tierras, como los otros, como seres inferiores, descalificados y discriminados desde una mirada voyeurista y excluyente.

En los antiguos textos de navegación de Cristóbal Colón se evidencia la forma en que los hombres miraban desde una posición de poder a las mujeres del mundo nuevo, convirtiéndolas en posesiones. Una mirada que como constatamos a través de los autores citados, aún se justifica y continúa perpetuando por medio de los mecanismos hegemónicos y globalizadores de la Colonialidad del Poder, donde el Otro queda siempre en desventaja, convirtiendo a la colonialidad en la cara oculta de la modernidad.

Así mismo, hemos analizado la posibilidad de un cambio que se establece desde la resistencia a esa mirada perversa. Un cambio que reivindica desde la sombra, desde la contra-historia, que para Foucault nace con el relato de la lucha de poder detrás de las 
luchas de raza. Un cambio que viene de abajo, de las costas, de la otredad relatada y develada, dentro de lo que Mignolo llama un Paradigma-otro. Se implanta desde ese mundo oculto que habla por medio de las voces acalladas detrás de los relatos de las personas marginadas y explotadas que viven en la desigualdad. Es un paradigma que al replicar sus experiencias y dar crédito a esas voces, devela las necesidades de los marginados y abre las posibilidades de una vida mejor a ese ser humano considerado como El Otro, para que desde su propia diferencia se reivindique con respecto a los demás.

Es así como en este artículo se visualiza la posibilidad de resignificar las historias que nos hablan de de la otredad que viven tantas mujeres. Historias-otras que se escucharían desde una posición incluyente y horizontal, logrando que sus voces se expandan, produciendo nuevas formas de vincularse y relacionarse, que paulatinamente irían sembrando la esperanza que rompería con las cadenas de la desigualdad y la exclusión Nuestra América.

\section{Referencias bibliográficas}

Benhabib, S. (2006 [1992]) El ser y el otro en la ética contemporánea: Feminismo, comunitarismo y posmodernismo. Barcelona: Gedisa.

Bhabha, H. (1994.) El lugar de la cultura. Buenos Aires: Manantial.

Butler, J. (1990.) El género en disputa. México: UNAM.

Cixous, H. (1992) La risa de la Medusa. Prólogo. Barcelona:Anthropos.

Chakravorty Spivak, G. (2006). ¿Puede hablar el subalterno? Bogotá: Instituto Colombiano de Antropologíae Historia.

De Sousa Santos, B. (2006.) Conocer desde el Sur: Para una cultura política emancipatoria. Lima: Facultad de ciencias Sociales, Universidad Mayor.

Durán Luzio, J. (1999.) Entre la espada y el falo: la mujer americana bajo el conquistador europeo. Heredia: EUNA.

Fraser, N. (1997).Iustitia Interrupta. Reflexiones críticas desde La posición postsocialista. Bogotá: Facultad de Derecho, Universidad de los Andes y Siglo del Hombre.

Foucault, M. (1992). Genealogía del racismo. Madrid. Las ediciones de la Piqueta. 
Gregorio Gil, C. (1998) Migración femenina: su impacto en las relaciones de género. Madrid: Narcea.

Irigaray, Luce (1982). Ese sexo que no es uno. Madrid: Editorial Saltes.

Mignolo, W, (2003). Historias locales/diseños globales. Colonialidad, conocimientos subalternos y pensamiento fronterizo. Madrid: EdicionesAkal.

Mignolo, W. (2007.) La Idea de América Latina. Barcelona: Gedisa.

Quijano, A. (2000.) Colonialidad del poder, eurocentrismo y América Latina. En Edgardo Lander, La Colonialidad del saber: Eurocentrismo y Ciencias Sociales. Perspectivas Latinoamericanas. Caracas: Clacso.

Mora, Rodríguez, L. A. (2009). La conquista del sexo. En Revista Senderos, 31, N .94. Pág.427-438. https://dialnet.unirioja.es/servlet/articulo?codigo=3091044

Rivera Cusicanqui, S. (1996). Ser mujer indígena, chola o birlocha en la Bolivia postcolonial de los años 90. La Paz: Plural editores.

Sassen, S. (1998.) Hacia un análisis feminista de la economía global, en Los espectros de la globalización. Buenos Aires: Fondo de Cultura Económica. 